\title{
Signs of Reduced Basal Progenitor Levels and Cortical Neurogenesis in Human Fetuses with Open Spina Bifida at 11-15 Weeks of Gestation
}

\author{
Simone A. Fietz, ${ }^{1,2}$ Takashi Namba, ${ }^{2}$ Holger Kirsten, ${ }^{3}$ Wieland B. Huttner, ${ }^{2}$ and $\odot$ Robert Lachmann ${ }^{4,5,6,7}$ \\ ${ }^{1}$ Institute of Veterinary Anatomy, Histology and Embryology, University of Leipzig, 04103 Leipzig, Germany, ${ }^{2}$ Max Planck Institute of Molecular Cell \\ Biology and Genetics, 01307 Dresden, Germany, ${ }^{3}$ Institute for Medical Informatics, Statistics, and Epidemiology, University of Leipzig, 04107 Leipzig, \\ Germany, ${ }^{4}$ Department for Obstetrics and Gynecology, University Hospital Carl Gustav Carus, Technical University Dresden, 01307 Dresden, Germany, \\ ${ }^{5}$ Fetal Medicine Centre Dresden, 01156 Dresden, Germany, ${ }^{6}$ Fetal Medicine Centre Germany, Carl-Thiem-Klinikum, 03048 Cottbus, Germany, and \\ ${ }^{7}$ Lausitzer Seenlandklinikum Hoyerswerda, 02977 Hoyerswerda, Germany
}

Open spina bifida (OSB) is one of the most prevalent congenital malformations of the CNS that often leads to severe disabilities. Previous studies reported the volume and thickness of the neocortex to be altered in children and adolescents diagnosed with OSB. Until now, the onset and the underlying cause of the atypical neocortex organization in OSB patients remain largely unknown. To examine the effects of OSB on fetal neocortex development, we analyzed human fetuses of both sexes diagnosed with OSB between 11 and 15 weeks of gestation by immunofluorescence for established neuronal and neural progenitor marker proteins and compared the results with healthy controls of the same, or very similar, gestational age. Our data indicate that neocortex development in OSB fetuses is altered as early as 11 weeks of gestation. We observed a marked reduction in the radial thickness of the OSB neocortex, which appears to be attributable to a massive decrease in the number of deep- and upper-layer neurons per field, and found a marked reduction in the number of basal progenitors (BPs) per field in the OSB neocortex, consistent with an impairment of cortical neurogenesis underlying the neuronal decrease in OSB fetuses. Moreover, our data suggest that the decrease in BP number in the OSB neocortex may be associated with BPs spending a lesser proportion of their cell cycle in M-phase. Together, our findings expand our understanding of the pathophysiology of OSB and support the need for an early fetal therapy (i.e., in the first trimester of pregnancy).

Key words: basal progenitors; human; neocortex; neurogenesis; open spina bifida; prenatal development

\section{Significance Statement}

Open spina bifida (OSB) is one of the most prevalent congenital malformations of the CNS. This study provides novel data on neocortex development of human OSB fetuses. Our data indicate that neocortex development in OSB fetuses is altered as early as 11 weeks of gestation. We observed a marked reduction in the radial thickness of the OSB neocortex, which appears to be attributable a decrease in the number of deep- and upper-layer neurons per field, and found a marked reduction in the number of basal progenitors per field, indicating that impaired neurogenesis underlies the neuronal decrease in OSB fetuses. Our findings support the need for an early fetal therapy and expand our understanding of the pathophysiology of OSB.

\section{Introduction}

Open spina bifida (OSB), also referred to as myelomeningocele or spina bifida aperta, is a congenital malformation of the CNS caused by the incomplete closure of the neural tube at the end of the first month of pregnancy (Mitchell et al., 2004; Fletcher and Brei, 2010; Greene and Copp, 2014; Copp et al., 2015; Brei and Houtrow, 2017). OSB is associated with a very high prevalence, and members of the light microscopy facility of the Max Planck Institute of Molecular Cell Biology and Genetics, and of the Biolmaging Core Facility of the University of Leipzig, for outstanding support.

The authors declare no competing financial interests.

Correspondence should be addressed to Wieland B. Huttner at huttner@mpi-cbg.de or Robert Lachmann at robert.lachmann@fetalmedicinecentre.de.

https://doi.org/10.1523/JNEUROSCI.0192-19.2019

Copyright $\odot 2020$ the authors 
affecting $\sim 1$ per 1000 births worldwide (Copp et al., 2015). Approximately three-fourths of the affected children survive to adulthood; however, they live with significant, lifelong morbidity, including intellectual and psychosocial abnormalities, bowel and bladder dysfunction, and orthopedic disabilities (Bowman et al., 2001). Brain anomalies that are characteristically associated with OSB include hypoplasia of the corpus callosum, ArnoldChiari malformation (Type II), and fetal-onset hydrocephalus (Adzick, 2013; Greene and Copp, 2014; Smith and Krynska, 2015). Previous studies reported the neocortex to be structurally altered in children with OSB relative to a normally developing control group (Fletcher et al., 2005; Juranek et al., 2008; Juranek and Salman, 2010; Treble et al., 2013). Specifically, neocortical volume and surface area were found to be decreased in neocortical regions posterior to the frontal lobe, including the cingulate, temporal, parietal, and occipital lobe of children with OSB compared with healthy controls (Fletcher et al., 2005; Juranek et al., 2008). Moreover, alterations in neocortical thickness were observed in the neocortex of OSB individuals with inferior parietal and temporal regions, exhibiting a thinner neocortex relative to the control group (Juranek et al., 2008; Juranek and Salman, 2010; Treble et al., 2013). Until now, the onset as well as the underlying cause of this atypical neocortex organization in OSB patients remain largely unknown.

The neocortex contains six neuronal layers with two major classes of neurons: glutamatergic projection neurons $(\sim 80 \%)$, which are born in the dorsal telencephalon and migrate radially into the cortical plate (CP) in a birth date-dependent inside-out manner; and GABAergic interneurons $(\sim 20 \%)$, which are mainly born in the ventral telencephalon and migrate tangentially to reach their destination in the developing neocortex (Wonders and Anderson, 2006; Han and Sestan, 2013; Hansen et al., 2013). The overwhelming majority of neocortical neurons are generated during embryonic and fetal development. Projection neurons mainly originate from two types of neural progenitor cells (NPCs): apical progenitors (APs) and basal progenitors (BPs) (Florio and Huttner, 2014; De Juan Romero and Borrell, 2015; Montiel et al., 2016; Namba and Huttner, 2017). APs are the primary NPCs, the cell bodies of which reside in the ventricular zone (VZ), the apical-most layer of the developing cortical wall. They comprise neuroepithelial cells, which transform into apical (or ventricular) radial glia at the onset of neurogenesis (Kriegstein and Götz, 2003; Götz and Huttner, 2005); and the apical intermediate progenitors, also known as short neural precursors (Gal et al., 2006; Stancik et al., 2010). All three AP subtypes display apical cell polarity and a basal process, which spans the cortical wall throughout the cell cycle in neuroepithelial cells and apical radial glia, and retracts from the basal lamina for mitosis in apical intermediate progenitors (Rakic, 1972; AakuSaraste et al., 1997; Chenn et al., 1998; Götz and Huttner, 2005; Gal et al., 2006; Marthiens and ffrench-Constant, 2009). Before the onset of neurogenesis, neuroepithelial cells mainly undergo symmetric proliferative divisions (Rakic, 1995). With the onset of neurogenesis, apical radial glia start dividing asymmetrically, thereby giving rise to BPs that accumulate in the subventricular zone (SVZ), adjacent to the VZ (Haubensak et al., 2004; Miyata et al., 2004; Noctor et al., 2004). BPs lack apical cell polarity and comprise two major subtypes: the process-lacking basal intermediate progenitors (bIPs) and the process-containing basal (or outer) radial glia (bRG) (Attardo et al., 2008; Fietz et al., 2010; Hansen et al., 2010; Reillo et al., 2011). In contrast to rodent BPs, which mostly undergo symmetric neurogenic (i.e., consumptive) divisions, the majority of human BPs are able to proliferate and to self-renew. This higher proliferative potential results in a massively expanded SVZ, leads to a higher neuronal output, and thus a more expanded neocortex in humans and nonhuman primates (Hansen et al., 2010; Lui et al., 2011; Betizeau et al., 2013; Gertz et al., 2014; Molnár and Pollen, 2014; De Juan Romero and Borrell, 2015; Namba and Huttner, 2017).

To examine the effects of OSB on fetal neocortex development, we analyzed human fetuses diagnosed with OSB between 11 and 15 weeks of gestation by immunofluorescence for neuronal and NPC marker proteins and compared the results with healthy controls of the same, or very similar, gestational age. Our data indicate that the radial thickness of the developing cortical wall is markedly reduced in the developing OSB neocortex and that the number of deep- and upper-layer neurons per field are massively decreased in affected fetuses, which does not seem to be attributable to cell death. Instead, we found a marked reduction in the number of BPs per field, suggesting that impaired neurogenesis underlies the neuronal decrease in OSB fetuses. Moreover, our data indicate that BPs spend a lesser proportion of their cell cycle in M-phase, thus providing evidence for the notion that the decrease in BP number per field observed in the developing OSB neocortex may be associated with alterations in the BP cell cycle. Together, our findings provide significant insights into the pathophysiology of OSB and support the importance of an early fetal therapy.

\section{Materials and Methods}

Brain tissue. A total of four human control and four OSB fetuses of either sex were used in this study. The age of the fetuses of the OSB group ranged from 11 to 15 weeks of gestation $(\mathrm{wg}): 11 \mathrm{wg}(11 \mathrm{wg}+1 \mathrm{~d}$ of gestation $[\mathrm{dg}]), 12 \mathrm{wg}(12 \mathrm{wg}+2 \mathrm{dg}), 15 \mathrm{wg}(15 \mathrm{wg}+1 \mathrm{dg}, 15 \mathrm{wg}+6 \mathrm{dg})$. The age of the fetuses of the control group ranged from 10 to 16 weeks of gestation: $10 \mathrm{wg}(10 \mathrm{wg}+0 \mathrm{dg}), 12 \mathrm{wg}(12 \mathrm{wg}+0 \mathrm{dg}), 15 \mathrm{wg}(15 \mathrm{wg}+5$ $\mathrm{dg}), 16 \mathrm{wg}(16 \mathrm{wg}+1 \mathrm{dg})$.

All OSB and control fetuses, except for the $16 \mathrm{wg}$ control brain (see below), were obtained from the Klinik und Poliklinik für Frauenheilkunde und Geburtshilfe, University Hospital Carl Gustav Carus of the Technische Universität Dresden (Dresden, Germany). The age of the fetuses was assessed by ultrasound measurements of crown-rump length and/or other criteria of developmental stage determination. Brain tissue was obtained with informed written maternal consent, with approval of the local University Hospital Ethical Review Committees. Pregnancies were carefully investigated by ultrasound. The ultrasound equipment used was Philips EPIQ 7G, 4D-Offline-Analysis Software QLAB 10.1, transducers C9-2, C5-1, X5-1, X6-1, C10-3v, L12-3, L18-5, V6-2, L12-5, and GE E8 Expert (Zipf), 4D Offline-Analysis Software 4DView 17, and transducers RAB 4-8-D and RIC 6-12-D. Data assessed in all sessions included loops sagittal/parasagittal views of the fetal head, brain, and face at 11-13 weeks and DICOM data. The midsagittal view was used for measurement of nuchal translucency. Pregnancies of the OSB group were terminated after prenatal diagnosis of OSB. All fetal brains of the OSB group showed a brainstem (BS)/BS to occipital bone (BSOB) ratio above the 95th centile, a Single-Line-Sign, and cisterna magna width $<5$ th centile. In all fetal brains of the OSB group, neural tube defect was visible in the direct assessment of the fetal spine (Lachmann et al., 2011; Scheier et al., 2011). Pregnancies of the control group were terminated on the basis of social or medical indication. Only medical indications not known to affect brain development (e.g., amnion infection) were included in the present study. In all fetal brains of the control group, the $\mathrm{BS} / \mathrm{BSOB}$ ratio and cisterna magna width were in normal range, the Two-Line-Sign was visible, and the direct assessment of the fetal spine showed no sign of abnormalities (Fig. 1). After surgical abortion, fetuses were immediately placed at $4^{\circ} \mathrm{C}$, and brains were dissected in ice-cold PBS, fixed for at least $24 \mathrm{~h}$ at $4^{\circ} \mathrm{C}$ in $4 \%$ PFA in $120 \mathrm{~mm} \mathrm{~PB}, \mathrm{pH} 7.4$, and stored in $\mathrm{PBS}$ at $4^{\circ} \mathrm{C}$ until processing. 
A

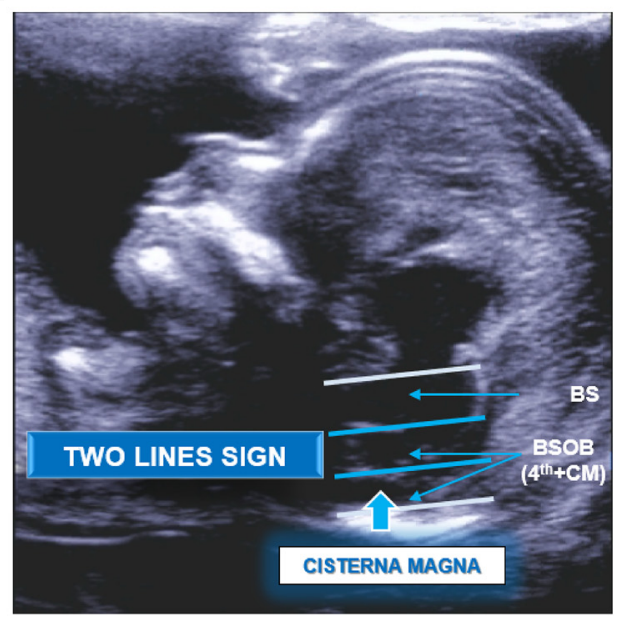

B

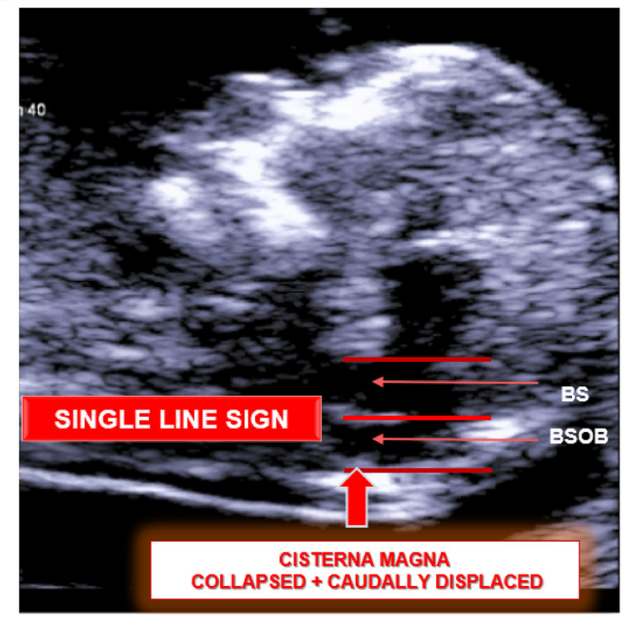

Figure 1. Ultrasonic assessment of the posterior brain in a control fetus and a fetus diagnosed with OSB. $\boldsymbol{A}, \boldsymbol{B}$, Ultrasonic scan showing the posterior brain of a control fetus $(\boldsymbol{A})$ and a fetus diagnosed with OSB $(B)$ at 12 weeks of gestation. Assessment of the posterior brain was performed using BS, BSOB diameter, cisterna magna width, single line sign, and two lines sign as indicated.

A

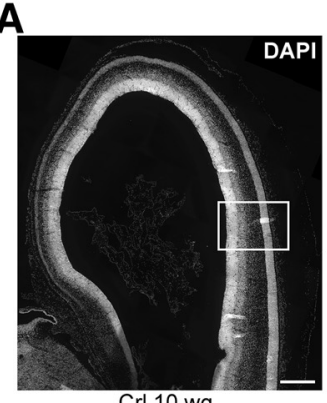

$\mathrm{Crl} 10 \mathrm{wg}$

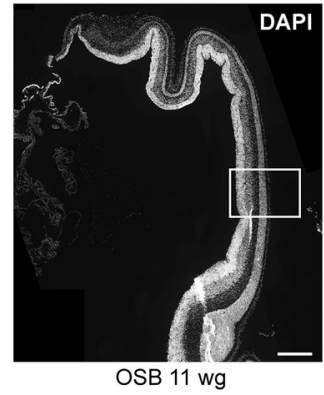

B

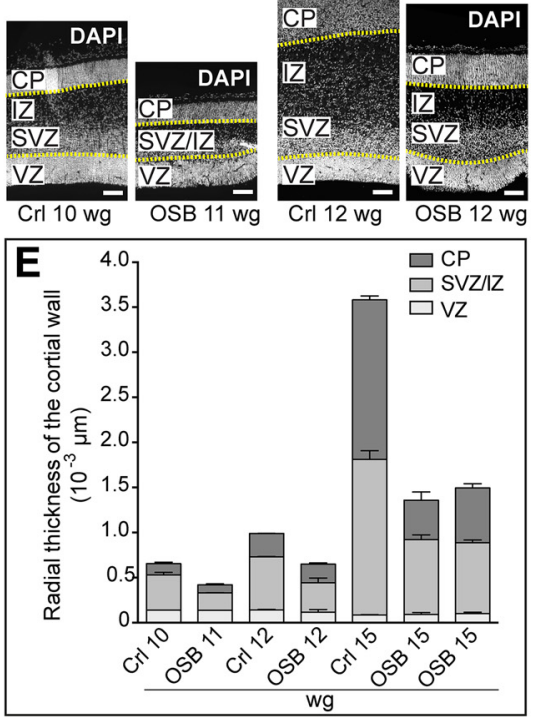

D

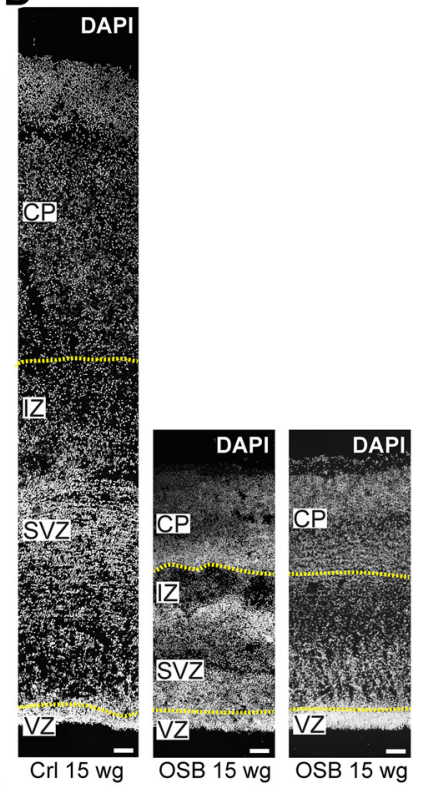

Figure 2. Fetuses with OSB show a marked reduction in the radial thickness of the CP and SVZ/IZ.A, Overview of the cortical wall, stained with DAPI, of a control (Crl) fetus of 10 weeks of gestation $(\mathrm{wg})$ (top) and a fetus of 11 weeks of gestation diagnosed with OSB (bottom). White boxes represent the areas shown at higher magnification in $\boldsymbol{B}$. Scale bars, $500 \mu \mathrm{m}$. $\boldsymbol{B}-\boldsymbol{D}$, Dorsolateral cortical wall, stained with DAPI, of a control (crl) fetus of 10, 12, or 15 weeks of gestation and a fetus of 11,12 , or 15 weeks of gestation diagnosed with OSB. $\boldsymbol{B}$, Images correspond to the areas indicated by the white boxes in $A$. $C, D$, Images correspond to those areas at the indicated later stages of cortical development. Bottom dotted lines indicate the boundary between the VZ and SVZ. Top dotted lines indicate the boundary between the IZ and CP. Scale bars, $100 \mu \mathrm{m}$. E, Radial thickness of the VZ, SVZ/IZ, and CP of control (crl) fetuses from 10, 12, and 15 weeks of gestation and fetuses from 11, 12, and 15 weeks of gestation diagnosed with OSB. Data are from two different sections each. Error bars indicate the individual variation from the mean.

PFA-fixed neocortical tissue from a human $16 \mathrm{wg}$ control fetus (age determination by standard criteria) was obtained from the Human Development Biology Resource, provided by the Joint MRC/Wellcome Trust (MR/R006237/1) Human Dev Biol Resource (http://www. hdbr.org), as described previously (Kalebic et al., 2019).

Immunocytochemistry. Brain tissue was dehydrated in 30\% sucrose in PBS until it sank to the bottom, embedded in Tissue-Tek (Sakura Finetek), and stored at $-20^{\circ} \mathrm{C}$. Cryosections were cut at $14-16 \mu \mathrm{m}$ and stored at $-20^{\circ} \mathrm{C}$. Telencephalon was cut coronally. All sections were heated for $1 \mathrm{~h}$ at $90^{\circ} \mathrm{C}$ in $0.01 \mathrm{M}$ citrate buffer, $\mathrm{pH}$ 6, permeabilized with $0.3 \%$ Triton X-100 in PBS, quenched with $0.1 \mathrm{~m}$ glycine, and subjected to an immunohistochemistry protocol as described previously (Fietz et al., 2010). Primary antibodies were incubated overnight at $4^{\circ} \mathrm{C}$, and secondary antibodies were incubated for $1 \mathrm{~h}$ at room temperature. The following primary antibodies were used: Tbr1 (1:200, Millipore, AB10554), Brn2 (1:200, Santa Cruz Biotechnology, sc-6029), Ki67 (1:200, DakoCytomation, M 7240), Pax6 (1:100, Biozol, BLD901301), Tbr2 (1:100, R\&D Systems, AF6166), nestin (1:200, Abcam, ab27952), GFAP (1:200, Sigma Millipore, G3893), Par3 (1:200, Millipore, 07-330), aPKC (1:200, BD Transduction Laboratories, 610207), ZO-1 (1:200, Invitrogen, 33-9100), activated caspase 3 (1: 200, C8487, Sigma Millipore), and phosphohistone H3 (PH3, 1:200, Millipore, 06-570). Donkey secondary antibodies coupled to Alexa$488,-555$, and -647 (1:500, Invitrogen) were used. All sections were counterstained with DAPI (1:500, Sigma Millipore), mounted in Mowiol (Merck Biosciences), and kept at $4^{\circ} \mathrm{C}$. 
A
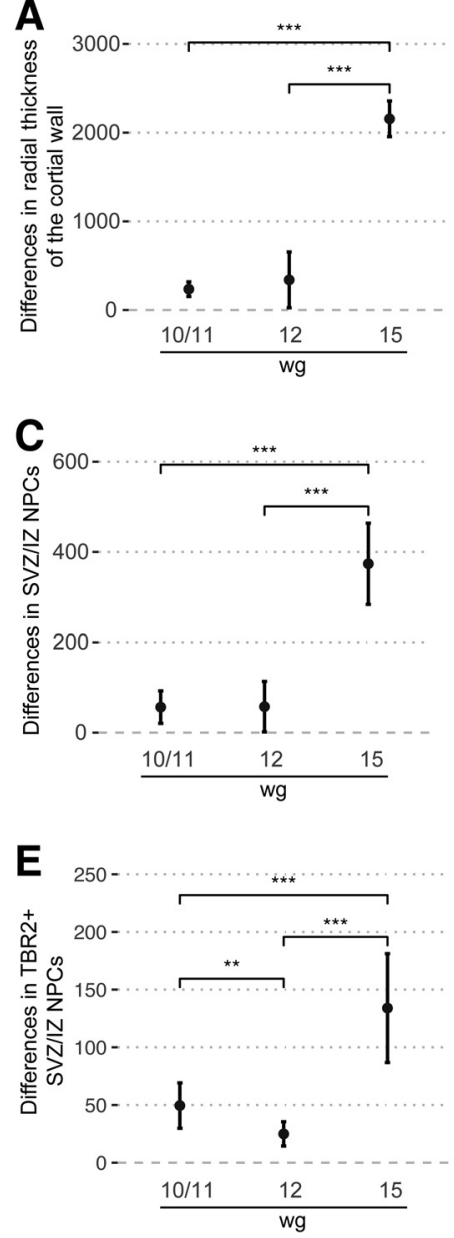

B
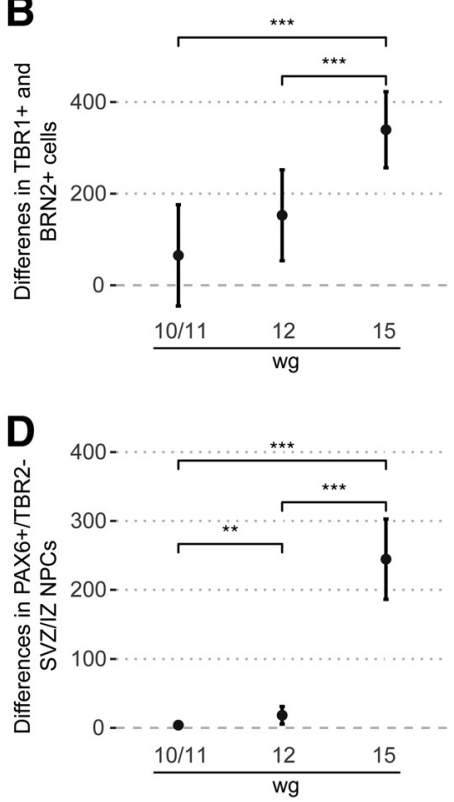

$\mathrm{CP}$ ), and the length of the ventricular surface were determined using Fiji software. Quantification of the radial thickness of the cortical wall and zones was performed on two different cortical sections of each brain. Plots showing radial thickness of the cortical wall, neuronal, NPC, and PH3 cell counts were generated in GraphPad Prism software. Cell counts shown represent mean \pm SEM. Radial thicknesses shown represent mean \pm individual variation from the mean. Development of differences in radial thickness of the cortical wall, neuronal, and NPC cell counts between OSB neocortex and corresponding controls over time were analyzed in R 3.5.3 (R Core Team, 2019) applying the multcomp package, version 1.4-10 (Hothorn et al., 2008). For this, the mean value of each parameter was compared between the OSB neocortex and corresponding controls at $10 / 11,12$, and 15 gestational weeks, respectively, using ANOVA considering OSB samples and corresponding controls as grouping factor. In cases where values were available from two OSB samples, contrasts were analyzed with both OSB samples being equally weighted. To analyze whether differences in the mean value of each parameter between OSB and control samples differ between the individual gestational weeks, pairwise differences were compared as previously described (Altman and Bland, 2003). Plots showing differences of indicated parameters were generated in $\mathrm{R}$ 3.5.3 (R Core Team, 2019). Differences represent mean $\pm 95 \%$ CI.

\section{Results}

\section{Radial thickness is markedly reduced in} the fetal OSB neocortex

We first examined whether and, if so, to what extent, the telencephalic diameter (i.e., the radial thickness) of the neocortex is altered during fetal development between 10 and 15 gestational week healthy controls and 11-15 gestational week fetuses diagnosed with OSB, all obtained

Image acquisition. Fluorescence images used for quantification of cells were acquired with a Carl Zeiss LSM 510 or Leica Microsystems SP8 confocal laser-scanning microscope, using a $40 \times$ objective. Fluorescence images used for radial thickness measurement were acquired with a Leica Microsystems SP8 confocal laser-scanning microscope or a Carl Zeiss Axioplan 2 OptiGrid confocal microscope, using $10 \times$ or $20 \times$ objectives. All images shown represent single optical sections and were processed using Fiji or Photoshop software (Adobe). Cortical zones were identified as described previously (Fietz et al., 2010; Sauerland et al., 2018). In brief, the $\mathrm{VZ}$ was identified as a densely packed cell layer that lines the lateral ventricle and whose nuclei exhibit radial morphology. The SVZ was identified as a cell layer adjacent to the VZ that exhibit a looser and sparser cell arrangement than the VZ. The intermediate zone (IZ) was identified as a cell layer between the SVZ and the CP that exhibits a very low cell density. The CP was identified as a densely packed cell layer adjacent to the IZ.

Experimental design and statistical analysis. Quantification of cells for the parameters indicated was performed on three different cortical sections of each brain using Fiji software with a Multiclass Cell Counter plug-in (Schindelin et al., 2012). The fluorescence signal of single channels was counted using grayscale. Neuronal and NPC cell counts were expressed as the number of cells per $100 \mu \mathrm{m}$ ventricular surface and were compared between the control and OSB groups using two-tailed unpaired Student's $t$ test. $p$ values $<0.05$ were considered significant. The radial thickness of the entire cortical wall, the cortical zones (VZ, SVZ/IZ, and processed under identical conditions. To this end, we analyzed sections of the neocortex stained with DAPI, which allows the distinction of the various cortical zones based on their nucleoarchitecture. This revealed that the radial thickness of the cortical wall was markedly reduced in fetuses with OSB compared with controls of the same, or very similar, gestational age (Fig. $2 A-D)$. Importantly, this reduction was detected at all gestational stages, with its magnitude being greatest at 15 weeks of gestation (Figs. 2D, 3A). Of note, analysis of the individual cortical zones showed that the reduction in radial thickness was more pronounced for the CP and the SVZ/IZ than for the VZ (Fig. 2E).

\section{Both deep-layer and upper-layer neurons are markedly reduced in the fetal OSB neocortex}

To determine the cellular correlate of the reduction in radial thickness, we next analyzed cortical sections for the expression of neuronal markers, that is, TBR1 and BRN2 characteristically expressed by early-born, deep-layer neurons and late-born, upperlayer neurons of the CP, respectively (Fig. 4) (He et al., 1989; Bulfone et al., 1995; Hevner, 2007; Molyneaux et al., 2007; Toma and Hanashima, 2015; Glatzle et al., 2017). This revealed that, in 


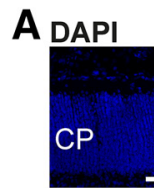

B

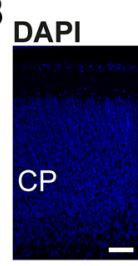

$C_{\text {DAPI }}$

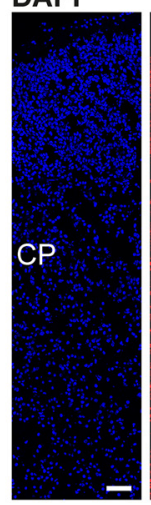

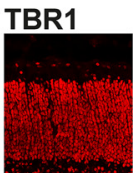

$\mathrm{Crl} 10 \mathrm{wg}$

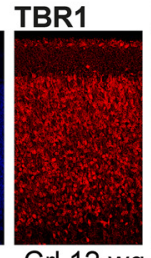

$\mathrm{Crl} 12 \mathrm{wg}$

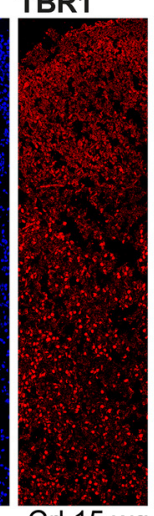

$\mathrm{Crl} 15 \mathrm{wg}$
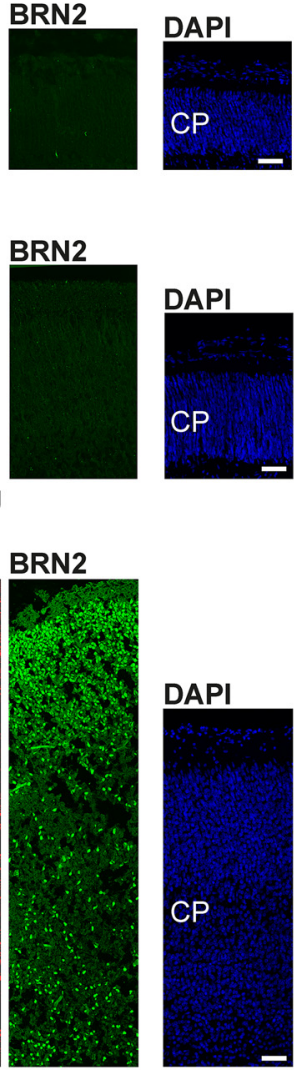

DAPI
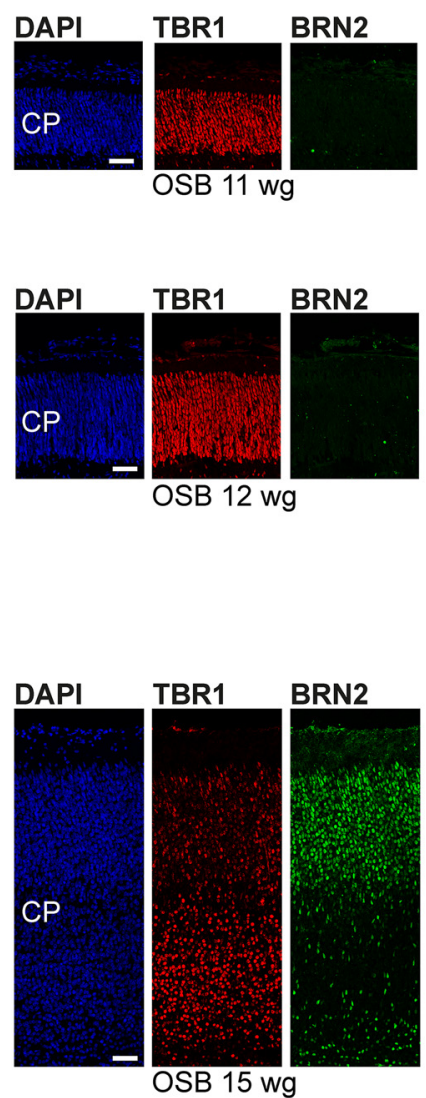

OSB $12 \mathrm{wg}$
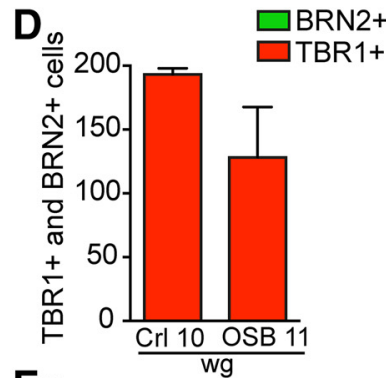

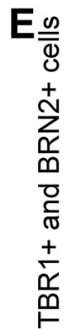

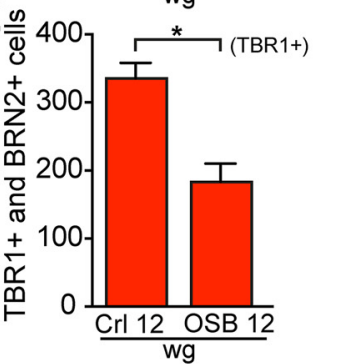

$\mathbf{F}$

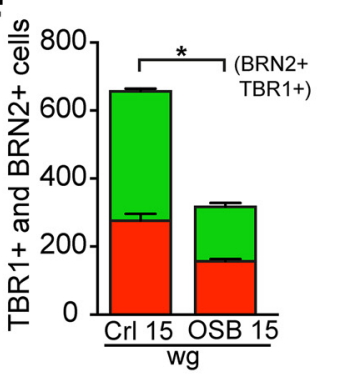

Figure 4. Fetuses with OSB show a marked reduction in neuron number in the (P. A-C, Double-immunofluorescence for TBR1 (red) and BRN2 (green), combined with DAPI staining (blue), on cortical sections of control (crl) fetuses of $10(\boldsymbol{A}$, left), 12 ( $\boldsymbol{B}$, left), and 15 ( $\boldsymbol{C}$, left) weeks of gestation (wg) and of fetuses of 11 ( $\boldsymbol{A}$, right), 12 ( $\boldsymbol{B}$, right), and 15 ( $\boldsymbol{C}$, right) weeks of gestation diagnosed with OSB. The bottom margin of the images corresponds to the apical boundary of the CP. Scale bars, $50 \mu \mathrm{m}$. $\boldsymbol{D}-\boldsymbol{F}$, Quantification of TBR1 ${ }^{+}$(red) deep-layer and BRN2 ${ }^{+}$(green) upper-layer neurons, expressed as number of cells per $100 \mu \mathrm{m}$ ventricular surface, in the (P of control (crl) fetuses of $10(\boldsymbol{D}), 12(\boldsymbol{E})$, and $15(\boldsymbol{F})$ weeks of gestation (wg) and of fetuses from $11(\boldsymbol{D}), 12(\boldsymbol{E})$, and $15(\boldsymbol{F})$ weeks of gestation diagnosed with OSB. Data are mean \pm SEM and are from three different cortical sections each. ${ }^{*} p<0.05$, statistically significant differences of TBR ${ }^{+}$neurons $(\boldsymbol{E}, \boldsymbol{F})$ and BRN2 $^{+}$neurons $(\boldsymbol{F})$ between crl and OSB fetuses.

fetuses with OSB, as in control fetuses, TBR $1^{+}$neurons were born first (i.e., before 11 weeks of gestation) and mainly accumulated in the deep layers of the CP (Fig. 4A,B), whereas BRN2 neurons were born at later stages of cortical development (i.e., after 12 weeks of gestation) and mainly accumulated in the upper layers of the CP (Fig. 4C). Hence, these data indicated that the general sequence of deep-layer and upper-layer neurogenesis is preserved in fetuses diagnosed with OSB. Quantification of the $\mathrm{TBR}^{+}{ }^{+}$and the BRN2 ${ }^{+}$neurons in the $\mathrm{CP}$ showed that both of these classes of neurons were markedly reduced in the developing neocortex of fetuses diagnosed with OSB compared with that of the corresponding controls (Fig. $4 D-F$ ). Again, this reduction was detected at all gestational stages analyzed; however, its magnitude was greatest at 15 weeks of gestation (Figs. 3B, $4 F$ ).

The decrease in neuron number in the fetal OSB neocortex is not due to cell death

The decrease in neuron number observed in the neocortex of fetuses diagnosed with OSB could be a result of increased neuronal cell death. We therefore examined DAPI-stained cortical sections of control and OSB fetuses for the presence of pyknotic and/or fragmented nuclei. This revealed that the overwhelming majority of nuclei showed no obvious signs of pyknosis and/or karyorrhexis (data not shown). To corroborate this, we analyzed cortical sections of OSB fetuses by immunohistochemistry for activated caspase 3 (Fig. 5), a specific marker of programmed cell death (Thornberry and Lazebnik, 1998; Slee et al., 2001; Lee and McKinnon, 2009). At all stages analyzed, the percentage of apoptotic cells in the various zones of the OSB neocortex examined was $<1 \%$, with the lowest percentage $(<0.03 \%)$ being observed for the $15 \mathrm{wg}$ CP (Table 1). Thus, the incidence of apoptosis of progenitor cells and neurons in the fetal OSB neocortex was as low as previously shown for healthy fetal human neocortex (Simonati et al., 1997, 1999; Chan and Yew, 1998; Rakic and Zecevic, 2000) and therefore could not account for the decrease in neuron number observed in the developing neocortex of fetuses diagnosed with OSB.

The AP pool size is not reduced in the fetal OSB neocortex In light of the lack of increased apoptosis in the fetal OSB neocortex, we investigated whether the reduction in neuron number observed in the neocortex of human fetuses diagnosed with OSB was due to impaired cortical neurogenesis. To this end, we analyzed the pool sizes of the major classes of NPCs and first focused on APs as the primary NPCs. Specifically, we analyzed cortical sections by triple-immunofluorescence for the expression of the proliferation marker KI67 and the transcription factors PAX6 and TBR2 (Fig. 6), both known to be characteristically expressed by distinct NPC subtypes (Götz et al., 1998; Englund et al., 2005; Fietz et al., 2010; Hansen et al., 2010; Reillo et al., 2011; Betizeau et al., 2013). Quantification of NPCs in the VZ revealed no marked differences between fetal control and OSB neocortex 

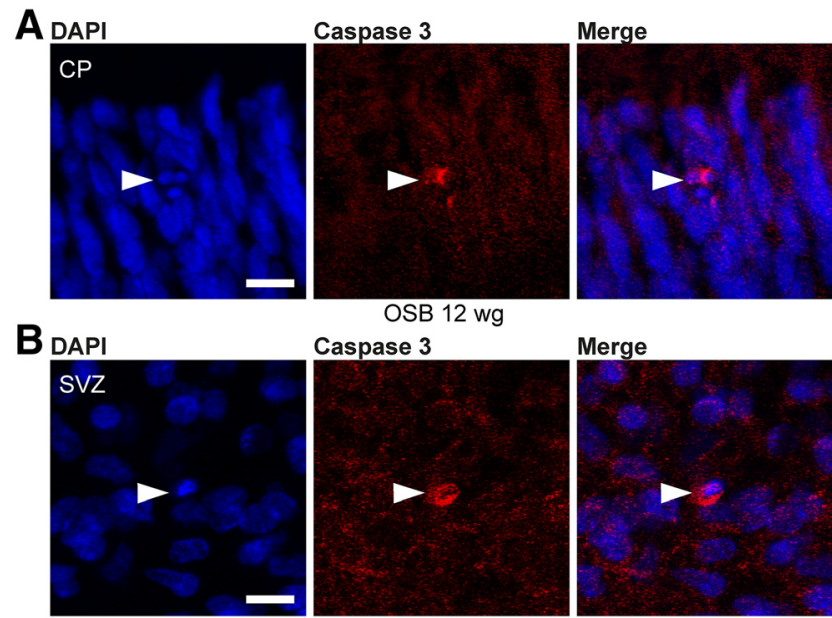

Merge
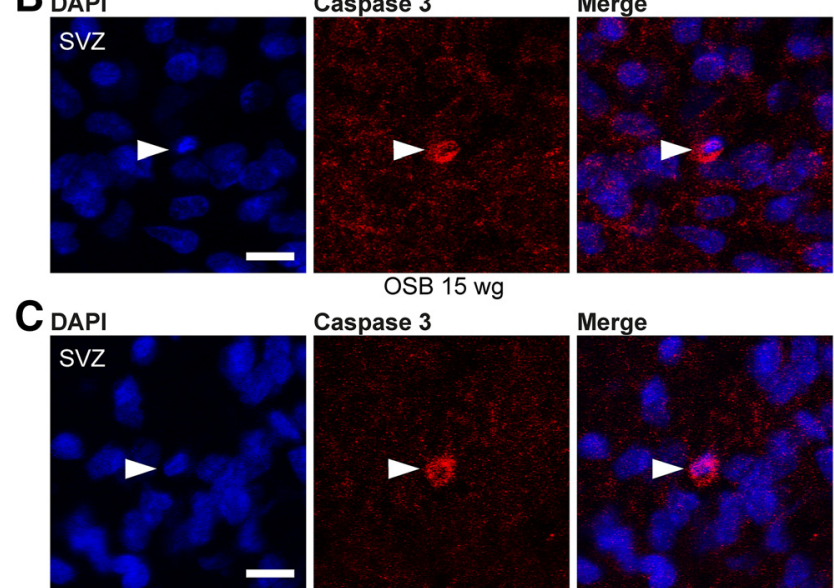

OSB $15 \mathrm{wg}$
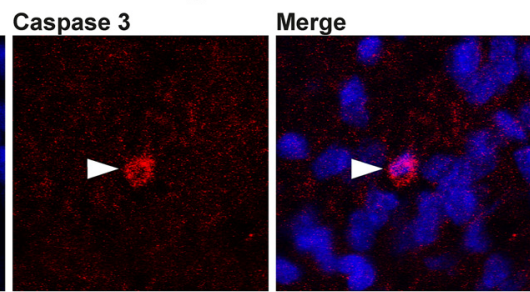

OSB $15 \mathrm{wg}$

Figure 5. Identification of apoptotic cells by immunohistochemistry for activated caspase 3. $A-C$, Immunohistochemistry for activated caspase 3 (red), combined with DAPI staining (blue), on sections of the $C P(A)$ and $\operatorname{SVZ}(\boldsymbol{B}, \boldsymbol{C})$ of fetuses of $12(\boldsymbol{A})$ and $15(\boldsymbol{B}, \boldsymbol{C})$ weeks of gestation (wg) diagnosed with OSB. Arrowheads indicate activated caspase 3 -expressing cells. Scale bars, $10 \mu \mathrm{m}$.

Table 1. Percentage of apoptotic cells, identified by immunohistochemistry for activated caspase 3 , in the cortical zones of a fetus each of 11, 12, and 15 weeks of gestation diagnosed with $\mathrm{OSB}^{a}$

\begin{tabular}{llll}
\hline $\begin{array}{l}\text { Developmental stage } \\
\text { (weeks of gestation) }\end{array}$ & Cortical zone & & \\
\cline { 2 - 4 } CP & SVZ/IZ & VZ \\
\hline 11 & $0.064 \pm 0.012$ & $0.894 \pm 0.024$ & $0.254 \pm 0.011$ \\
12 & $0.079 \pm 0.014$ & $0.773 \pm 0.032$ & $0.163 \pm 0.024$ \\
15 & $0.028 \pm 0.007$ & $0.271 \pm 0.089$ & $0.097 \pm 0.015$ \\
\hline
\end{tabular}

${ }^{a}$ Data are mean \pm SEM and are from 3 different cortical sections each.

(Figs. 6, 7A). Similar to the control neocortex, the overwhelming majority of the NPCs in the VZ of fetuses diagnosed with OSB were PAX6 ${ }^{+}$and TBR2 ${ }^{-}$(Fig. $7 B, D, F$ ). Importantly, the number of these PAX $6{ }^{+} / \mathrm{TBR}^{-}{ }^{-}$NPCs in the VZ did not differ markedly between fetal control and OSB neocortex (Fig. $7 B, D, F$ ). This indicates that the AP pool size is largely unaffected in the developing neocortex of fetuses diagnosed with OSB compared with that of controls.

Upon further characterization, we found the intermediate filament proteins nestin and GFAP to be expressed in the AP cell body and in the radially extending AP cell processes in the fetal OSB neocortex, as has been observed in physiologically developing human neocortex (Fig. 8) (Zecevic, 2004; Howard et al., 2006; Fietz et al., 2010). Immunohistochemistry for the apical domain markers PAR3 and APKC, known to be associated with the apical cell cortex of APs (Aaku-Saraste et al., 1996; Manabe et al., 2002; Wodarz and Huttner, 2003), and for $\mathrm{ZO}-1$, which in embryonic neocortex has been shown to be associated with the apical adherens junction belt (AakuSaraste et al., 1996; Manabe et al., 2002; Wodarz and Huttner,

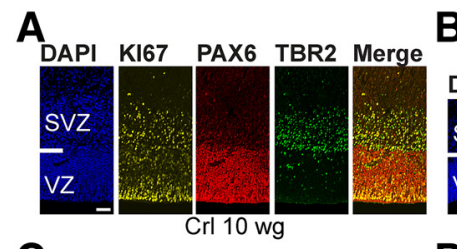

B

\section{C}

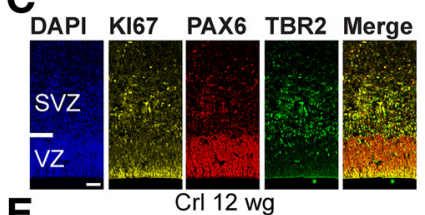

$\mathrm{E}$

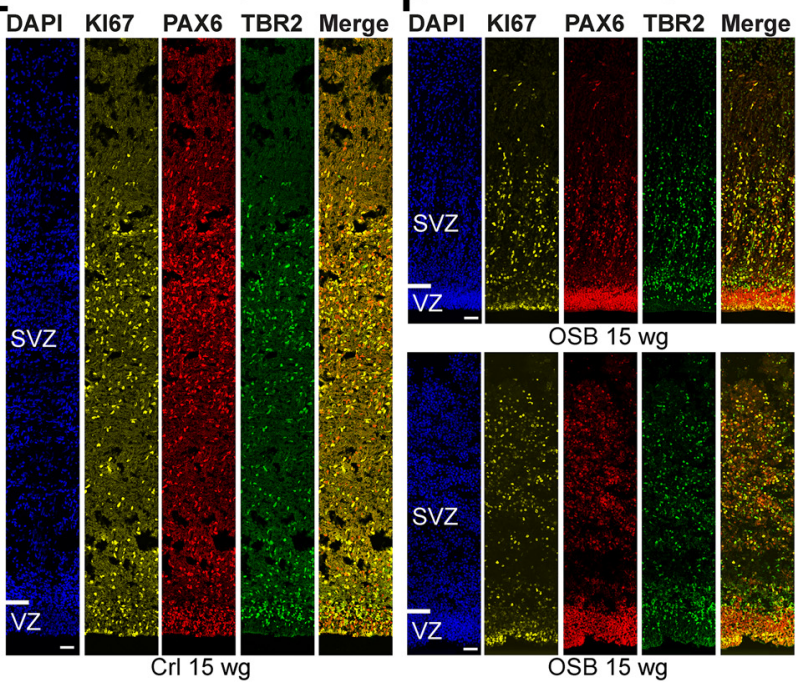

Figure 6. The neocortex of fetuses with OSB shows a marked reduction in the number of BPs. Triple-immunofluorescence for K167 (yellow), PAX6 (red), and TBR2 (green), combined with DAPI staining (blue), on cortical sections of control (crl) fetuses of $10(\boldsymbol{A}), 12(\boldsymbol{C})$, and $15(\boldsymbol{E})$ weeks of gestation $(\mathrm{wg})$ and of fetuses of $11(\boldsymbol{B}), 12(\boldsymbol{D})$, or $15(\boldsymbol{F})$ weeks of gestation diagnosed with OSB. Merged images represent combined immunofluorescence for KI67, PAX6, and TBR2. The top margin of the images corresponds to the basal boundary of the SVZ. Scale bars, $50 \mu \mathrm{m}$.

2003), revealed that all three proteins were highly concentrated near the ventricular surface of the developing cortical wall of fetuses diagnosed with OSB (Fig. 9). These findings indicate that the expression of molecular markers characteristic of AP identity and the apical cell polarity of APs seem to be largely unaffected in the developing neocortex of fetuses diagnosed with OSB.

\section{The BP pool size is markedly decreased in the fetal}

OSB neocortex

We next focused our analysis on the pool size of BPs, which generate the majority of neurons in the developing neocortex (Haubensak et al., 2004; Miyata et al., 2004; Noctor et al., 2004; Hansen et al., 2010; Fietz and Huttner, 2011; Lui et al., 2011; Betizeau et al., 2013; Namba and Huttner, 2017). Intriguingly, we found that the number of NPCs, identified by KI67 immunohistochemistry, was markedly decreased in the SVZ/IZ of fetuses diagnosed with OSB compared with that of corresponding controls (Figs. 6, Fig. 7A). This reduction was observed at all gestational stages analyzed, with its magnitude being greatest at 15 weeks of gestation (Figs. 3C, 7A). To investigate whether this reduction was attributable to a specific $\mathrm{BP}$ subpopulation, we 

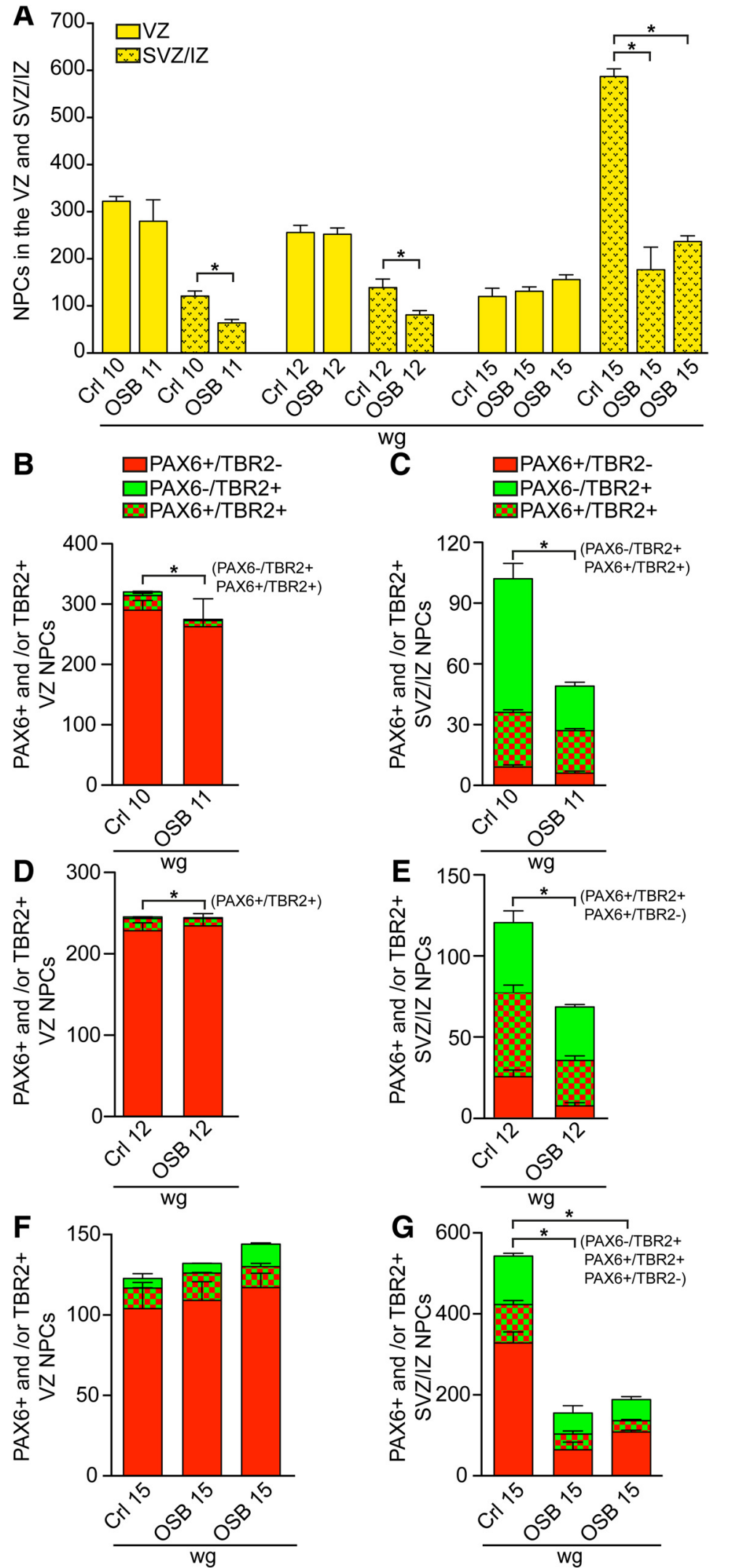

exploited previous findings (Fietz et al., 2010; Florio et al., 2015) that the vast majority of human bRG expresses PAX6 but not TBR2, whereas most human bIPs are $\mathrm{TBR}^{+}{ }^{+}$PAX $^{-} / \mathrm{TBR}^{+}{ }^{+}$or $\left.\mathrm{PAX}_{6}{ }^{+} / \mathrm{TBR}^{+}{ }^{+}\right)$. We therefore quantified, in fetal control and OSB neocortex, the number of $\mathrm{KI}_{6}{ }^{+} \mathrm{NPCs}$ in the SVZ/IZ that express PAX6 and/or TBR2. In fetal control neocortex, the proportion of $\mathrm{PAX}^{+} / \mathrm{TBR}^{-}$NPCs relative to the PAX6 ${ }^{-} / \mathrm{TBR}^{+}$and $\mathrm{PAX}^{+}{ }^{+}$ TBR2 ${ }^{+}$NPCs in the SVZ/IZ increased with the progression of neurogenesis (Fig. $7 C, E, G$ ), consistent with an increasing proportion of bRG among the BPs. At all stages analyzed, we observed a marked reduction in the number of $\mathrm{TBR}^{+}{ }^{+} \mathrm{PAX}^{-} / \mathrm{TBR}^{+}, \mathrm{PAX}^{+}{ }^{+} / \mathrm{TBR}^{+}{ }^{+}$) NPCs, thought to mostly represent bIPs, and of PAX6 ${ }^{+} / \mathrm{TBR}^{-}{ }^{-}$NPCs, thought to mostly represent bRG, in the SVZ/IZ of fetuses diagnosed with OSB compared with that of corresponding controls (Fig. $7 C, E, G)$. Intriguingly, the magnitude of the reduction was greatest at 15 weeks of gestation, with the number of both BP subtypes (i.e., bIPs and bRG) being similarly affected (Figs. 3D,E, 7G).

To corroborate these observations, we analyzed sections from an additional control fetus of $16 \mathrm{wg}(16 \mathrm{wg}+1 \mathrm{dg})$, obtained and processed under similar conditions, by triple-immunofluorescence for the expression of KI67, PAX6, and TBR2 (Fig. 10A). Again, no marked differences were observed in the number of $\mathrm{KI}^{+} 7^{+}$ $\left(\mathrm{PAX}_{6}{ }^{+} / \mathrm{TBR}^{-}{ }^{-}, \mathrm{PAX}_{6}{ }^{+} / \mathrm{TBR}^{+}{ }^{+}, \mathrm{PAX}^{-}{ }^{-} /\right.$ $\mathrm{TBR}^{+}{ }^{+}$) NPCs between the VZ of fetal 16 wg control and OSB fetuses of similar gestational age (Fig. $10 B, C$ ). However, we found the number of $\mathrm{KI} 7^{+} \mathrm{NPC}$ to be markedly decreased in the SVZ/IZ of 15 wg OSB fetuses compared with that of 16 wg control, which was attributable to a reduction in both $\mathrm{BP}$ subtypes $\left(\mathrm{PAX}^{+}{ }^{+} /\right.$ TBR2 $^{-}$bRG and PAX6 $^{+} / \mathrm{TBR}{ }^{+}$or PAX $6^{-} / \mathrm{TBR}^{+}{ }^{+}$bIPs) (Fig. $\left.10 \mathrm{~B}, \mathrm{D}\right)$. Together, we conclude that (1) the massive reduction in the $\mathrm{BP}$ pool size underlies the decrease in neuron number observed in the neocortex of fetuses diagnosed with OSB; and (2) this reduction involves both bIPs and bRG.

of gestation diagnosed with OSB. $\boldsymbol{A}-\mathbf{G}$, Data are mean \pm SEM and are from three different cortical sections each. ${ }^{*} p<0.05$, statistically significant differences of $\mathrm{KI}^{+} 7^{+} \mathrm{NPCS}(\boldsymbol{A})$, $\mathrm{PAX}^{+} /{ }^{\mathrm{TBR} 2} 2^{-} \mathrm{NPCS}(\boldsymbol{E}, \boldsymbol{G}), \mathrm{PAX}^{+}{ }^{+} / \mathrm{TBR} 2^{+} \mathrm{NPCS}(\boldsymbol{B}-\boldsymbol{E}, \boldsymbol{G})$, and $\mathrm{PAX6}^{-} / \mathrm{TBR2}^{+} \mathrm{NPCS}(\boldsymbol{B}, \boldsymbol{C}, \boldsymbol{G})$ between $\mathrm{Cr}$ and OSB fetuses. 
A
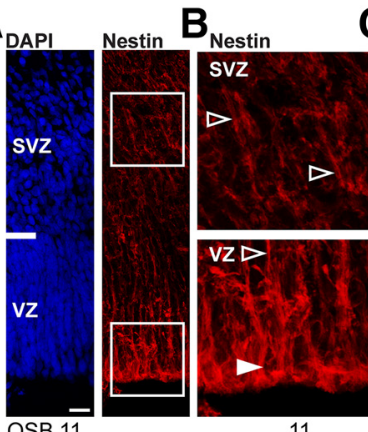

11
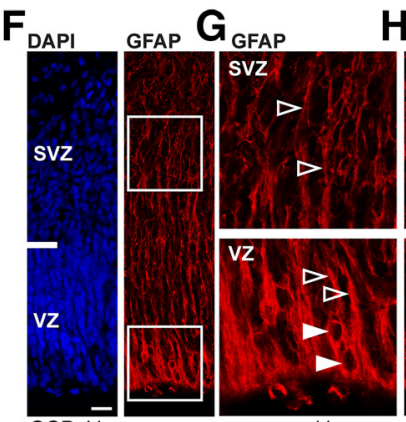

11

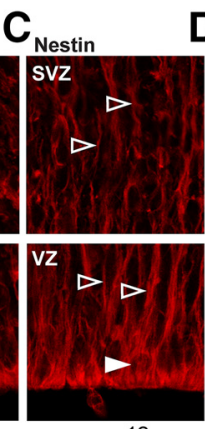

12

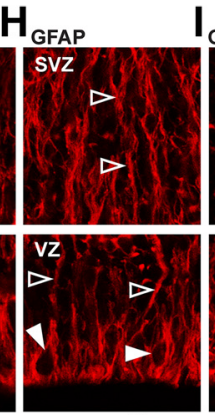

12

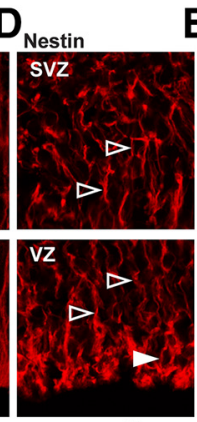

15

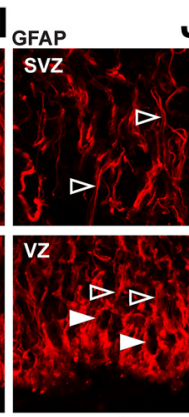

15

Figure 8. APs in the developing neocortex of fetuses diagnosed with OSB express nestin and GFAP. Immunohistochemistry for nestin $(\boldsymbol{A}-\boldsymbol{E}$, red) and GFAP $(\boldsymbol{F}-\boldsymbol{J}$, red), combined with DAPI staining in $(\boldsymbol{A}, \boldsymbol{F}$, blue), on cortical sections of fetuses of $11(\boldsymbol{A}, \boldsymbol{B}, \boldsymbol{F}, \boldsymbol{G}), 12$ $(\boldsymbol{C}, \boldsymbol{H}), 15(\boldsymbol{D}, \boldsymbol{I})$, and $15(\boldsymbol{E}, \boldsymbol{J})$ weeks of gestation $(\mathrm{wg})$ diagnosed with OSB. $\boldsymbol{A}, \boldsymbol{F}$, Boxed areas are shown at higher magnification in $\boldsymbol{B}$ and $\boldsymbol{G}$, respectively. The areas shown in the images in $\boldsymbol{C}-\boldsymbol{E}$ and $\boldsymbol{H} \boldsymbol{-} \boldsymbol{J}$ correspond to the areas shown in $\boldsymbol{A}, \boldsymbol{B}$ and $\boldsymbol{F}, \boldsymbol{G}$, respectively, at the indicated later stages of cortical development. Closed arrowheads indicate nestin-expressing $(\boldsymbol{B}-\boldsymbol{E})$ and GFAP-expressing $(\boldsymbol{G}-\boldsymbol{J})$ cell bodies. Open arrowheads indicate nestin-expressing $(\boldsymbol{B}-\boldsymbol{E})$ or GFAP-expressing $(\boldsymbol{G}-\boldsymbol{J})$ cell processes. Scale bars, $20 \mu \mathrm{m}$.

BPs in the neocortex of 15 gestational week fetus with OSB spend a lesser proportion of their cell cycle in

M-phase than control BPs

As the percentage of apoptotic cells in the SVZ/IZ was extremely low $(<1 \%)$ at all stages analyzed (Table 1$)$, NPC cell death does not appear to underlie the decrease in BP number in the OSB neocortex. We therefore sought to explore other potential causes of this decrease. To this end, we performed double-immunofluorescence for $\mathrm{KI} 67$ and the mitosis marker $\mathrm{PH} 3$ on cortical sections of control and OSB fetuses (Fig. 11 A,B) and quantified the percentage of $\mathrm{KI}_{67}{ }^{+}$cells in the $\mathrm{VZ}$ and $\mathrm{SVZ}$ that were $\mathrm{PH}{ }^{+}$. Remarkably, at 15 gestational week, when we had observed the highest reduction in BP cell number, we found that the percentage of $\mathrm{KI}_{67}{ }^{+}$cells that were also $\mathrm{PH} 3{ }^{+}$was essentially the same for the fetus with OSB and the control fetus in the VZ, but was reduced to half in the fetus with OSB in the SVZ compared with the control fetus (Fig. 11C). These data indicate that, relative to the entire duration of their cell cycle (as revealed by KI67 immunoreactivity), BPs in the 15 gestational week OSB neocortex spend only half the time in the $\mathrm{PH}^{+}$portion of M-phase than the BPs of the corresponding control fetus, whereas no such difference exists between OSB and control APs. These findings are consistent with at least two distinct scenarios. First, on the assumption that the absolute length of $\mathrm{M}$-phase was the same for control and OSB BPs, our data would imply that BPs in the developing OSB neocortex double the length of their interphase compared with those of the developing control neocortex. This in turn would imply a twofold reduction in the BP cell division rate in the neocortex of OSB fetuses, providing an explanation for the observed decrease in neurogenesis. Second, on the assumption that the absolute length of interphase

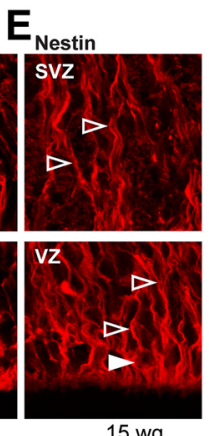

$J_{\text {GFAP }}$
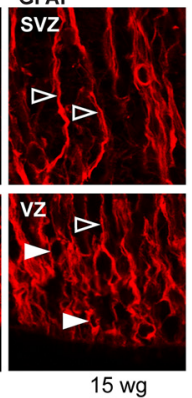

was the same for control and OSB BPs, our data would imply a twofold reduction in the duration of M-phase BPs in the developing OSB neocortex compared with those of the developing control neocortex. In this context, it is interesting to note that a shortening of metaphase of NPCs has recently been implicated in the reduction of their proliferative capacity (Mora-Bermudez et al., 2016). Hence, the second scenario would also be consistent with the observed phenotype of the OSB neocortex.

Similar to the 15 gestational week fetus, we found the percentage of cycling cells that were in M-phase to be reduced in the SVZ of fetuses with OSB compared with that of corresponding controls at 11 and 12 gestational weeks, although this difference was not statistically significant (data not shown). This was consistent with the notion that both fetuses showed a less pronounced reduction in BP cell number compared with that of 15 gestational week. Together, our data imply that changes in cell cycle dynamics might be associated with the decrease in BP number observed in the neocortex of fetuses with OSB and that their extent increases with the progression of the phenotype.

\section{Discussion}

This study provides novel insight into neocortex development of human fetuses diagnosed with OSB. Our data indicate that the neocortex of such fetuses between 11 and 15 weeks of gestation is characterized by a marked reduction in radial thickness, especially of the CP and SVZ/IZ, thereby complementing previous studies showing neocortex thickness to be altered in children and adolescents diagnosed with OSB compared with healthy controls (Juranek et al., 2008; Treble et al., 2013). Indeed, we demonstrate that the reduction in neocortex thickness appears to be already apparent as early as in the first trimester of intrauterine life. Moreover, our data are consistent with previous findings of a reduced head size observed in OSB fetuses between 11 and 24 weeks of gestation (Wald et al., 1980; Nicolaides et al., 1986; Bernard et al., 2012; Karl et al., 2012; Khalil et al., 2013; Bahlmann et al., 2015).

We show that the decrease in radial thickness observed in the fetal OSB neocortex seems to be attributable to a massive decrease in deep- and upper-layer neurons, which is not primarily linked to an increase in neuronal cell death. Instead, we found evidence for a marked reduction in the number of BPs known to generate the majority of neurons in the human neocortex, thus indicating that impaired neurogenesis may underlie the decrease in neuron number observed in the fetal OSB neocortex. Given that the greatest magnitude of the cortical alterations was observed at week 15 of gestation, our data support the notion that the damage to the neural tissue in OSB fetuses is progressive during gestation (Adzick, 2013; Copp et al., 2015). Our data suggest that the reduction in BP number observed in the fetal OSB neocortex is not caused by BP cell death; however, they offer the possibility that 
alterations in the BP cell cycle length, specifically a slowdown in its cell division rate, may underlie the decrease in neurogenesis of the fetal OSB neocortex. Thus, our findings support the assumption that reduced NPC proliferation may account for the atypical cortical organization, involving thinning of the cortical wall, in the OSB brain (Del Bigio, 2010; Treble et al., 2013). In this regard, it has been reported that, in a model of fetal-onset hydrocephalus, a condition that is predominantly associated with OSB (Owen-Lynch et al., 2003; Adzick, 2013; Araujo Júnior et al., 2016), cell cycle progression of cortical NPCs is impaired due to S-phase blockade, leading to a reduction in the number of cortical NPCs. Further analyses, including specific cell cycle assays in animal models of OSB and primary human fetal cortical NPC cultures of affected fetuses, are needed to precisely evaluate cell cycle changes of NPCs in the fetal OSB neocortex and to examine the extent to which aberrations in the NPC cell cycle progression account for the decrease in neurogenesis observed in the fetal OSB neocortex.

A possible alternative explanation for the observed reduction in BP cell number in the OSB fetuses could be that the development of the neocortex is delayed in fetuses with OSB compared with that of controls. If so, given that the number of APs, in contrast to the number of BPs, is known to progressively decline in the human control neocortex between 10 and 16 gestational weeks (Fietz et al., 2010), one would then expect not only the number of BPs to be reduced, but also the number of APs to be substantially increased, compared with corresponding controls. However, our data indicate that the AP cell pool is largely unaffected in the fetal OSB neocortex compared with that of controls. Hence, these findings do not support the possibility that a delayed neurogenesis represents the major underlying cause for the observed reduction in BP cell number.

Intriguingly, APs and BPs fundamentally differ in their accessibility to nutrients and oxygen. APs have access to the ventricular lumen, and thus directly receive nutrients and proliferation signals present in the CSF, in addition to those present in the VZ vasculature (Veening and Barendregt, 2010; Lehtinen and Walsh, 2011; Homem et al., 2015; Bueno and Garcia-Fernàndez, 2016). However, as BPs lack contact to the ventricular surface and thus to the supply of nutrients by the CSF, the SVZ vasculature appears to be an important site for nutrient supply of BPs (Javaherian and Kriegstein, 2009; Stubbs et al., 2009). Compression of small blood vessels in the periventricular compartment has been described as one of the mechanisms of injury in hydrocephalus in the context of OSB (Del Bigio, 2010). Thus, one possible scenario might be that insufficient supply of nutrients and oxygen as a consequence of vascular compression following ventriculomegaly affects BP behavior, leading to reduced BP proliferation in the fetal OSB neocortex. Regarding this, it has been reported that changes in the nutritional state are able to impact NPC cycle control mechanisms and cell proliferation (Lacar et al., 2012; Homem et al., 2015). The direct supply of CSF to APs might enable these cells to compensate for a reduced blood supply in the germinal zones, which could explain why APs, compared with $\mathrm{BPs}$, are less affected in the fetal OSB neocortex. More extensive studies, including a broader range of OSB neocortex samples from different developmental stages, are necessary to gain deeper understanding of the mechanisms that underlie impaired neocortex development in fetuses diagnosed with OSB.

OSB is a chronic and irreversible disease. Thus, therapeutic strategies that interrupt progressive pathological processes are important to manage the disorder and prevent complications (Smith and Krynska, 2015). Especially, fetal therapy has been a major focus over the last years. Fetal surgical repair of OSB, which is generally performed between 19 and 25 weeks of gestation, has been associated with improved neurological outcomes and reduced need for invasive procedures during childhood compared with standard, postnatal surgical repair (Adzick et al., 2011; Adzick, 2013; Moldenhauer, 2014; Copp et al., 2015; Araujo Júnior et al., 2016). Given that neocortex development in OSB fetuses is 

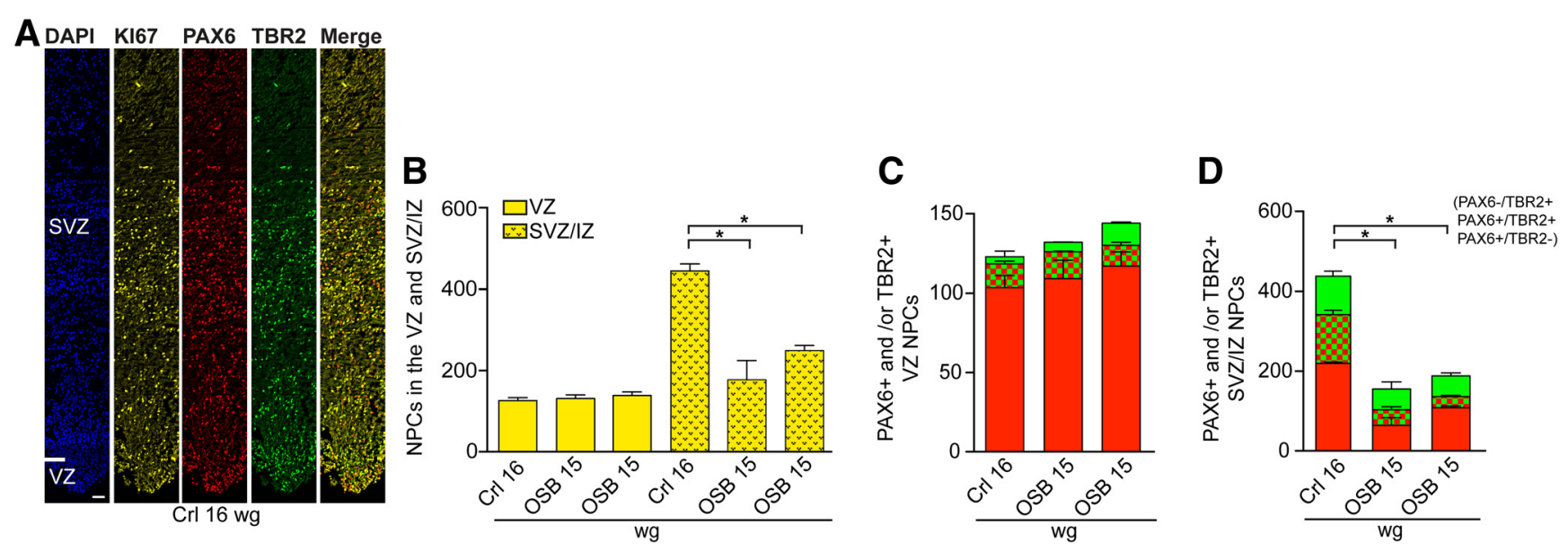

Figure 10. Comparative quantification of NPCs in the neocortical VZ and SVZ of a control fetus of $16 \mathrm{wg}$ and OSB fetuses of $15 \mathrm{wg}$. $\boldsymbol{A}$, Triple-immunofluorescence for KI67 (yellow), PAX6 (red), and TBR2 (green), combined with DAPI staining (blue), on a cortical section of a control (crl) fetus of 16 weeks of gestation (wg). Merged images represent combined immunofluorescence for KI67, PAX6, and TBR2. The top margin of the images corresponds to the basal boundary of the SVZ. Scale bars, $50 \mu \mathrm{m}$. B, Quantification of NPCs, identified by KI67 immunoreactivity, in the VZ (yellow) and SVZ (black/yellow), expressed as number of cells per $100 \mu \mathrm{m}$ ventricular surface, of a control (crl) fetus of $16 \mathrm{wg}$ and of fetuses of $15 \mathrm{wg}$ diagnosed with OSB. C, D, Quantification of PAX6 ${ }^{+} /$TBR2 $^{-}$(red), PAX6 ${ }^{-} / \mathrm{TBR2}^{+}$(green), and PAX6 ${ }^{+} / \mathrm{TBR2}{ }^{+}$(red/green) NPCs, identified by $\mathrm{KI} 67$ immunoreactivity, in the VZ (C) and SVZ (D), expressed as number of cells per $100 \mu \mathrm{m}$ ventricular surface, of a control (crl) fetus of $16 \mathrm{wg}$ and of fetuses of $15 \mathrm{wg}$ diagnosed with OSB. $\boldsymbol{B}-\boldsymbol{D}$, Data are mean \pm SEM and are from three different cortical sections each. ${ }^{*} p<0.05$, statistically significant differences of $\mathrm{KI} 67^{+} \mathrm{NPCs}(\boldsymbol{B}), \mathrm{PAX}^{+} / \mathrm{TBR2}{ }^{-} \mathrm{NPCS}(\boldsymbol{D}), \mathrm{PAX}^{+} / \mathrm{TBR2}{ }^{+} \mathrm{NPCS}_{(\boldsymbol{D})}$, and PAX6 ${ }^{-} / \mathrm{TBR2}^{+}$ NPCS $(\boldsymbol{D})$ between crl and OSB fetuses.

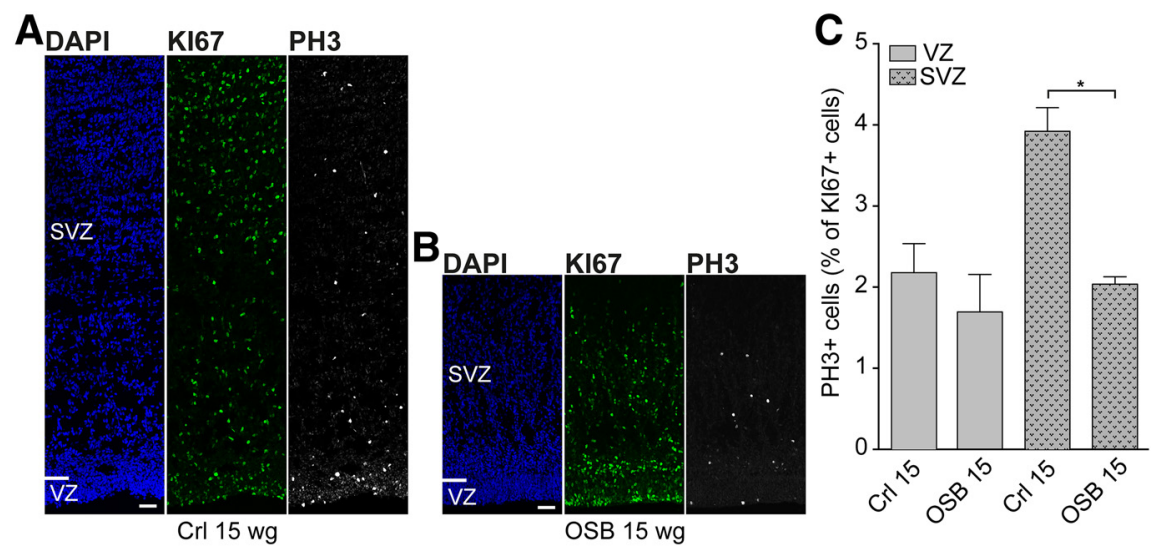

Figure 11. BPs in the neocortex of 15 gestational week fetus with OSB spend a lesser proportion of their cell cycle in M-phase than control BPs. A, B, Double-immunofluorescence for KI67 (green) and PH3 (white), combined with DAPI staining (blue), on cortical sections of a control (crl) fetus of 15 weeks of gestation $(\boldsymbol{A})$ and a fetus of 15 weeks of gestation diagnosed with OSB $(\boldsymbol{B})$. The top margin of the images corresponds to the basal boundary of the SVZ. Scale bars, $50 \mu \mathrm{m} . \boldsymbol{C}$, Quantification of cells in M-phase (as revealed by PH3 immunofluorescence), expressed as a percentage of cycling cells (as revealed by $\mathrm{KI} 67$ immunofluorescence), in the VZ (gray) and SVZ (gray/black) of a control (crl) fetus of 15 weeks of gestation and of a fetus of 15 weeks of gestation diagnosed with OSB. Data are mean \pm SEM and are from 3 (OSB) or 4 (crl) different cortical sections each. ${ }^{*} p<0.05$, statistically significant differences of $\mathrm{PH} 3{ }^{+}$cells $\left(\%\right.$ of $\mathrm{KI} 67^{+}$cells) between the crl and OSB fetus. studies are necessary to investigate whether surgical intervention before 19 weeks of gestation limits impaired neocortex development and thus further improve long-term neurological function.

In conclusion, our data indicate that the neocortex of OSB fetuses from 11 to 15 weeks of gestation is characterized by a marked reduction in radial thickness. This reduction appears to be attributable to a massive decrease in deep- and upper-layer neurons, most likely caused by a marked reduction in the number of $\mathrm{BPs}$, thus indicating that impaired neurogenesis might underlie the reduction in neuron number observed in the fetal OSB neocortex. Moreover, our data provide evidence for the notion that the decrease in BP number observed in the fetal OSB neocortex might be associated with alterations in the BP cell cycle. Together, our findings expand our understanding of the pathophysiology of OSB and support the need for an early fetal intervention. apparently altered as early as 11 weeks of gestation, our data support the need for an early OSB diagnosis and fetal repair. By using the midsagittal view for the measurement of nuchal translucency and assessment of BS-BSOB-ratio, cisterna magna width, and presence of a Single-Line-Sign for the identification of OSB fetuses between 11 and 13 weeks of gestation, this study provides further evidence for the notion that this method enables physicians to reliably identify fetal brain abnormalities, such as OSB, and cystic posterior fossa abnormalities, including DandyWalker syndrome, agenesis of the corpus callosum, and isolated cleft lip and palate at an early developmental stage (Lachmann et al., 2010, 2011, 2012, 2013, 2018; Lachmann, 2012, 2018). Further

\section{References}

Aaku-Saraste E, Hellwig A, Huttner WB (1996) Loss of occludin and functional tight junctions, but not ZO-1, during neural tube closure: remodeling of the neuroepithelium prior to neurogenesis. Dev Biol 180:664679.

Aaku-Saraste E, Oback B, Hellwig A, Huttner WB (1997) Neuroepithelial cells downregulate their plasma membrane polarity prior to neural tube closure and neurogenesis. Mech Dev 69:71-81.

Adzick NS (2013) Fetal surgery for spina bifida: past, present, future. Semin Pediatr Surg 22:10-17.

Adzick NS, Thom EA, Spong CY, Brock JW 3rd, Burrows PK, Johnson MP, Howell LJ, Farrell JA, Dabrowiak ME, Sutton LN, Gupta N, Tulipan NB, 
D’Alton ME, Farmer DL (2011) A randomized trial of prenatal versus postnatal repair of myelomeningocele. N Engl J Med 364:993-1004.

Altman DG, Bland JM (2003) Interaction revisited: the difference between two estimates. BMJ 326:219.

Araujo Júnior E, Eggink AJ, van den Dobbelsteen J, Martins WP, Oepkes D (2016) Procedure-related complications of open vs endoscopic fetal surgery for treatment of spina bifida in an era of intrauterine myelomeningocele repair: systematic review and meta-analysis. Ultrasound Obstet Gynecol 48:151-160.

Attardo A, Calegari F, Haubensak W, Wilsch-Bräuninger M, Huttner WB (2008) Live imaging at the onset of cortical neurogenesis reveals differential appearance of the neuronal phenotype in apical versus basal progenitor progeny. PLoS One 3:e2388.

Bahlmann F, Reinhard I, Schramm T, Geipel A, Gembruch U, von Kaisenberg CS, Schmitz R, Stupin J, Chaoui R, Karl K, Kalache K, Faschingbauer F, Ponnath M, Rempen A, Kozlowski P (2015) Cranial and cerebral signs in the diagnosis of spina bifida between 18 and 22 weeks of gestation: a German multicentre study. Prenat Diagn 35:228-235.

Bernard JP, Cuckle HS, Stirnemann JJ, Salomon LJ, Ville Y (2012) Screening for fetal spina bifida by ultrasound examination in the first trimester of pregnancy using fetal biparietal diameter. Am J Obstet Gynecol 207: 306.e1-5.

Betizeau M, Cortay V, Patti D, Pfister S, Gautier E, Bellemin-Ménard A, Afanassieff M, Huissoud C, Douglas RJ, Kennedy H, Dehay C (2013) Precursor diversity and complexity of lineage relationships in the outer subventricular zone of the primate. Neuron 80:442-457.

Bowman RM, McLone DG, Grant JA, Tomita T, Ito JA (2001) Spina bifida outcome: a 25-year prospective. Pediatr Neurosurg 34:114-120.

Brei T, Houtrow A (2017) Spina bifida. J Pediatr Rehabil Med 10:165-166.

Bueno D, Garcia-Fernàndez J (2016) Evolutionary development of embryonic cerebrospinal fluid composition and regulation: an open research field with implications for brain development and function. Fluids Barriers CNS 13:5.

Bulfone A, Smiga SM, Shimamura K, Peterson A, Puelles L, Rubenstein JL (1995) T-brain-1: a homolog of brachyury whose expression defines molecularly distinct domains within the cerebral cortex. Neuron 15:63-78.

Chan WY, Yew DT (1998) Apoptosis and bcl-2 oncoprotein expression in the human fetal central nervous system. Anat Rec 252:165-175.

Chenn A, Zhang YA, Chang BT, McConnell SK (1998) Intrinsic polarity of mammalian neuroepithelial cells. Mol Cell Neurosci 11:183-193.

Copp AJ, Adzick NS, Chitty LS, Fletcher JM, Holmbeck GN, Shaw GM (2015) Spina bifida. Nat Rev Dis Primers 1:15007.

De Juan Romero C, Borrell V (2015) Coevolution of radial glial cells and the cerebral cortex. Glia 63:1303-1319.

Del Bigio MR (2010) Neuropathology and structural changes in hydrocephalus. Dev Disabil Res Rev 16:16-22.

Englund C, Fink A, Lau C, Pham D, Daza RA, Bulfone A, Kowalczyk T, Hevner RF (2005) Pax6, Tbr2, and Tbr1 are expressed sequentially by radial glia, intermediate progenitor cells, and postmitotic neurons in developing neocortex. J Neurosci 25:247-251.

Fietz SA, Huttner WB (2011) Cortical progenitor expansion, self-renewal and neurogenesis-a polarized perspective. Curr Opin Neurobiol 21:2335.

Fietz SA, Kelava I, Vogt J, Wilsch-Bräuninger M, Stenzel D, Fish JL, Corbeil D, Riehn A, Distler W, Nitsch R, Huttner WB (2010) OSVZ progenitors of human and ferret neocortex are epithelial-like and expand by integrin signaling. Nat Neurosci 13:690-699.

Fletcher JM, Brei TJ (2010) Introduction: spina bifida: a multidisciplinary perspective. Dev Disabil Res Rev 16:1-5.

Fletcher JM, Copeland K, Frederick JA, Blaser SE, Kramer LA, Northrup H, Hannay HJ, Brandt ME, Francis DJ, Villarreal G, Drake JM, Laurent JP, Townsend I, Inwood S, Boudousquie A, Dennis M (2005) Spinal lesion level in spina bifida: a source of neural and cognitive heterogeneity. J Neurosurg 102:268-279.

Florio M, Huttner WB (2014) Neural progenitors, neurogenesis and the evolution of the neocortex. Development 141:2182-2194.

Florio M, Albert M, Taverna E, Namba T, Brandl H, Lewitus E, Haffner C, Sykes A, Wong FK, Peters J, Guhr E, Klemroth S, Prüfer K, Kelso J, Naumann R, Nüsslein I, Dahl A, Lachmann R, Pääbo S, Huttner WB (2015) Human-specific gene ARHGAP11B promotes basal progenitor amplification and neocortex expansion. Science 347:1465-1470.

Gal JS, Morozov YM, Ayoub AE, Chatterjee M, Rakic P, Haydar TF (2006)
Molecular and morphological heterogeneity of neural precursors in the mouse neocortical proliferative zones. J Neurosci 26:1045-1056.

Gertz CC, Lui JH, LaMonica BE, Wang X, Kriegstein AR (2014) Diverse behaviors of outer radial glia in developing ferret and human cortex. J Neurosci 34:2559-2570.

Glatzle M, Hoops M, Kauffold J, Seeger J, Fietz SA (2017) Development of deep and upper neuronal layers in the domestic cat, sheep and pig neocortex. Anat Histol Embryol 46:397-404.

Götz M, Huttner WB (2005) The cell biology of neurogenesis. Nat Rev Mol Cell Biol 6:777-788.

Götz M, Stoykova A, Gruss P (1998) Pax6 controls radial glia differentiation in the cerebral cortex. Neuron 21:1031-1044.

Greene ND, Copp AJ (2014) Neural tube defects. Annu Rev Neurosci $37: 221-242$

Han W, Sestan N (2013) Cortical projection neurons: sprung from the same root. Neuron 80:1103-1105.

Hansen DV, Lui JH, Parker PR, Kriegstein AR (2010) Neurogenic radial glia in the outer subventricular zone of human neocortex. Nature 464: $554-561$.

Hansen DV, Lui JH, Flandin P, Yoshikawa K, Rubenstein JL, Alvarez-Buylla A, Kriegstein AR (2013) Non-epithelial stem cells and cortical interneuron production in the human ganglionic eminences. Nat Neurosci 16: 1576-1587.

Haubensak W, Attardo A, Denk W, Huttner WB (2004) Neurons arise in the basal neuroepithelium of the early mammalian telencephalon: a major site of neurogenesis. Proc Natl Acad Sci U S A 101:3196-3201.

He X, Treacy MN, Simmons DM, Ingraham HA, Swanson LW, Rosenfeld MG (1989) Expression of a large family of POU-domain regulatory genes in mammalian brain development. Nature 340:35-41.

Hevner RF (2007) Layer-specific markers as probes for neuron type identity in human neocortex and malformations of cortical development. J Neuropathol Exp Neurol 66:101-109.

Homem CC, Repic M, Knoblich JA (2015) Proliferation control in neural stem and progenitor cells. Nat Rev Neurosci 16:647-659.

Hothorn T, Bretz F, Westfall P (2008) Simultaneous inference in general parametric models. Biom J 50:346-363.

Howard B, Chen Y, Zecevic N (2006) Cortical progenitor cells in the developing human telencephalon. Glia 53:57-66.

Javaherian A, Kriegstein A (2009) A stem cell niche for intermediate progenitor cells of the embryonic cortex. Cereb Cortex 19 [Suppl 1]:i70-i77.

Juranek J, Salman MS (2010) Anomalous development of brain structure and function in spina bifida myelomeningocele. Dev Disabil Res Rev 16:23-30.

Juranek J, Fletcher JM, Hasan KM, Breier JI, Cirino PT, Pazo-Alvarez P, Diaz JD, Ewing-Cobbs L, Dennis M, Papanicolaou AC (2008) Neocortical reorganization in spina bifida. Neuroimage 40:1516-1522.

Kalebic N, Gilardi C, Stepien B, Wilsch-Bräuninger M, Long KR, Namba T, Florio M, Langen B, Lombardot B, Shevchenko A, Kilimann MW, Kawasaki H, Wimberger P, Huttner WB (2019) Neocortical expansion due to increased proliferation of basal progenitors is linked to changes in their morphology. Cell Stem Cell 24:535-550.e9.

Karl K, Benoit B, Entezami M, Heling KS, Chaoui R (2012) Small biparietal diameter in fetuses with spina bifida on 11-13-week and mid-gestation ultrasound. Ultrasound Obstet Gynecol 40:140-144.

Khalil A, Coates A, Papageorghiou A, Bhide A, Thilaganathan B (2013) Biparietal diameter at 11-13 weeks' gestation in fetuses with open spina bifida. Ultrasound Obstet Gynecol 42:409-415.

Kriegstein AR, Götz M (2003) Radial glia diversity: a matter of cell fate. Glia 43:37-43.

Lacar B, Herman P, Platel JC, Kubera C, Hyder F, Bordey A (2012) Neural progenitor cells regulate capillary blood flow in the postnatal subventricular zone. J Neurosci 32:16435-16448.

Lachmann R (2012) Correspondence regarding research letter published by Arigita et al. Prenat Diagn 32:201; author reply 202-203.

Lachmann R (2018) Comment on 'A prospective study on fetal posterior cranial fossa assessment for early detection of open spina bifida at 11-13 weeks' by Kose et al. Congenit Anom (Kyoto) 58:77.

Lachmann R, Picciarelli G, Moratalla J, Greene N, Nicolaides KH (2010) Frontomaxillary facial angle in fetuses with spina bifida at 11-13 weeks' gestation. Ultrasound Obstet Gynecol 36:268-271.

Lachmann R, Chaoui R, Moratalla J, Picciarelli G, Nicolaides KH (2011) 
Posterior brain in fetuses with open spina bifida at 11 to 13 weeks. Prenat Diagn 31:103-106.

Lachmann R, Sinkovskaya E, Abuhamad A (2012) Posterior brain in fetuses with Dandy-Walker malformation with complete agenesis of the cerebellar vermis at 11-13 weeks: a pilot study. Prenat Diagn 32:765-769.

Lachmann R, Sodre D, Barmpas M, Akolekar R, Nicolaides KH (2013) Midbrain and falx in fetuses with absent corpus callosum at 11-13 weeks. Fetal Diagn Ther 33:41-46.

Lachmann R, Schilling U, Brückmann D, Weichert A, Brückmann A (2018) Isolated cleft lip and palate: maxillary gap sign and palatino-maxillary diameter at 11-13 weeks. Fetal Diagn Ther 44:241-246.

Lee Y, McKinnon PJ (2009) Detection of apoptosis in the central nervous system. Methods Mol Biol 559:273-282.

Lehtinen MK, Walsh CA (2011) Neurogenesis at the brain-cerebrospinal fluid interface. Annu Rev Cell Dev Biol 27:653-679.

Lui JH, Hansen DV, Kriegstein AR (2011) Development and evolution of the human neocortex. Cell 146:18-36.

Manabe N, Hirai S, Imai F, Nakanishi H, Takai Y, Ohno S (2002) Association of ASIP/mPAR-3 with adherens junctions of mouse neuroepithelial cells. Dev Dyn 225:61-69.

Marthiens V, ffrench-Constant C (2009) Adherens junction domains are split by asymmetric division of embryonic neural stem cells. EMBO Rep 10:515-520.

Mitchell LE, Adzick NS, Melchionne J, Pasquariello PS, Sutton LN, Whitehead AS (2004) Spina bifida. Lancet 364:1885-1895.

Miyata T, Kawaguchi A, Saito K, Kawano M, Muto T, Ogawa M (2004) Asymmetric production of surface-dividing and non-surface-dividing cortical progenitor cells. Development 131:3133-3145.

Moldenhauer JS (2014) In utero repair of spina bifida. Am J Perinatol 31:595-604.

Molnár Z, Pollen A (2014) How unique is the human neocortex? Development 141:11-16.

Molyneaux BJ, Arlotta P, Menezes JR, Macklis JD (2007) Neuronal subtype specification in the cerebral cortex. Nat Rev Neurosci 8:427-437.

Montiel JF, Vasistha NA, Garcia-Moreno F, Molnár Z (2016) From sauropsids to mammals and back: new approaches to comparative cortical development. J Comp Neurol 524:630-645.

Mora-Bermudez F, Badsha F, Kanton S, Camp JG, Vernot B, Kohler K, Voigt B, Okita K, Maricic T, He Z, Lachmann R, Paabo S, Treutlein B, Huttner WB (2016) Differences and similarities between human and chimpanzee neural progenitors during cerebral cortex development. eLife 5:e18683.

Namba T, Huttner WB (2017) Neural progenitor cells and their role in the development and evolutionary expansion of the neocortex. Wiley Interdiscip Rev Dev Biol 6.

Nicolaides KH, Campbell S, Gabbe SG, Guidetti R (1986) Ultrasound screening for spina bifida: cranial and cerebellar signs. Lancet 2:72-74.

Noctor SC, Martínez-Cerdeno V, Ivic L, Kriegstein AR (2004) Cortical neurons arise in symmetric and asymmetric division zones and migrate through specific phases. Nat Neurosci 7:136-144.

Owen-Lynch PJ, Draper CE, Mashayekhi F, Bannister CM, Miyan JA (2003) Defective cell cycle control underlies abnormal cortical development in the hydrocephalic Texas rat. Brain 126:623-631.

R Core Team (2019) R: a language and environment for statistical computing. Vienna: R Foundation for Statistical Computing. https://www. R-project.org/.

Rakic P (1972) Mode of cell migration to the superficial layers of fetal monkey neocortex. J Comp Neurol 145:61-83.
Rakic P (1995) A small step for the cell, a giant leap for mankind: a hypothesis of neocortical expansion during evolution. Trends Neurosci 18:383-388.

Rakic S, Zecevic N (2000) Programmed cell death in the developing human telencephalon. Eur J Neurosci 12:2721-2734.

Reillo I, de Juan Romero C, García-Cabezas MÁ, Borrell V (2011) A role for intermediate radial glia in the tangential expansion of the mammalian cerebral cortex. Cereb Cortex 21:1674-1694.

Sauerland C, Menzies BR, Glatzle M, Seeger J, Renfree MB, Fietz SA (2018) The basal radial glia occurs in marsupials and underlies the evolution of an expanded neocortex in therian mammals. Cereb Cortex 28:145-157.

Scheier M, Lachmann R, Petros M, Nicolaides KH (2011) Threedimensional sonography of the posterior fossa in fetuses with open spina bifida at 11-13 weeks' gestation. Ultrasound Obstet Gynecol 38:625-629.

Schindelin J, Arganda-Carreras I, Frise E, Kaynig V, Longair M, Pietzsch T, Preibisch S, Rueden C, Saalfeld S, Schmid B, Tinevez JY, White DJ, Hartenstein V, Eliceiri K, Tomancak P, Cardona A (2012) Fiji: an opensource platform for biological-image analysis. Nat Methods 9:676-682.

Simonati A, Rosso T, Rizzuto N (1997) DNA fragmentation in normal development of the human central nervous system: a morphological study during corticogenesis. Neuropathol Appl Neurobiol 23:203-211.

Simonati A, Tosati C, Rosso T, Piazzola E, Rizzuto N (1999) Cell proliferation and death: morphological evidence during corticogenesis in the developing human brain. Microsc Res Tech 45:341-352.

Slee EA, Adrain C, Martin SJ (2001) Executioner caspase-3, -6, and -7 perform distinct, non-redundant roles during the demolition phase of apoptosis. J Biol Chem 276:7320-7326.

Smith GM, Krynska B (2015) Myelomeningocele: how we can improve the assessment of the most severe form of spina bifida. Brain Res 1619:84-90.

Stancik EK, Navarro-Quiroga I, Sellke R, Haydar TF (2010) Heterogeneity in ventricular zone neural precursors contributes to neuronal fate diversity in the postnatal neocortex. J Neurosci 30:7028-7036.

Stubbs D, DeProto J, Nie K, Englund C, Mahmud I, Hevner R, Molnár Z (2009) Neurovascular congruence during cerebral cortical development. Cereb Cortex 19 [Suppl 1]:i32-i41.

Thornberry NA, Lazebnik Y (1998) Caspases: enemies within. Science 281:1312-1316.

Toma K, Hanashima C (2015) Switching modes in corticogenesis: mechanisms of neuronal subtype transitions and integration in the cerebral cortex. Front Neurosci 9:274

Treble A, Juranek J, Stuebing KK, Dennis M, Fletcher JM (2013) Functional significance of atypical cortical organization in spina bifida myelomeningocele: relations of cortical thickness and gyrification with IQ and fine motor dexterity. Cereb Cortex 23:2357-2369.

Veening JG, Barendregt HP (2010) The regulation of brain states by neuroactive substances distributed via the cerebrospinal fluid; a review. Cerebrospinal Fluid Res 7:1.

Wald N, Cuckle H, Boreham J, Stirrat G (1980) Small biparietal diameter of fetuses with spina bifida: implications for antenatal screening. Br J Obstet Gynaecol 87:219-221.

Wodarz A, Huttner WB (2003) Asymmetric cell division during neurogenesis in Drosophila and vertebrates. Mech Dev 120:1297-1309.

Wonders CP, Anderson SA (2006) The origin and specification of cortical interneurons. Nat Rev Neurosci 7:687-696.

Zecevic N (2004) Specific characteristic of radial glia in the human fetal telencephalon. Glia 48:27-35. 